\title{
Metabolic status of rabbits under physiological adaptation to cage husbandry technology
}

\author{
Natalia Khokhlova ${ }^{1}$, Vladimir Semenyutin ${ }^{1}$, Viktor Eremenko ${ }^{2}$ \\ ${ }^{1}$ The Belgorod State Agrarian University named after V.Ya Gorin, 1 Vavilova Street, Belgorod region, Belgorod district, \\ Maysky village, 308503, Russia. \\ ${ }^{2}$ Kursk State Agricultural Academy named after I.I. Ivanov, 70 Karl Marx Street, Kursk, 305021, Russia.
}

\begin{abstract}
The article considers changes in biochemical blood parameters depending on the degree of adaptation process manifesting on the plantar surface of hind limbs of different sex rabbits and physiological state under cage husbandry technology. Groups of stud bucks (1st series), pregnant and lactating does (2nd and 3rd series of experiments) were formed according to the stages of structural changes depending on the stress of physiological regulatory processes of adaptation (the systematics proposed by R.M. Baevsky). The authors studied the following factors in serum: total protein, protein fractions (albumin, $\alpha-, \beta-, \gamma$-globulin), creatinine, total bilirubin, urea, uric acid, alanine aminotransferase (ALT), aspartate aminotransferase (AST), alkaline phosphatase, glucose triacylglycerol and cholesterol. At the stressed stage of regulatory systems the group of bucks showed a reduction of total bilirubin on the background of decrease of ALT, AST and alkaline phosphatase, which can testify to activation of liver function at this stage, and increase in bilirubin, ALT, AST with a simultaneous decrease in alkaline phosphatase, noted at the overstress stage of physiological adaptation regulatory processes, can testify to decrease in the functional activity of hepatocytes.Pregnant rabbits have the most pronounced compensatory reactions in the third stage of the adaptation process: the increase in absolute and relative $\gamma$-globulin values indicates the activation of immune factors. An increase in creatinine and urea levels during the gestation period, against a background of developing adaptive changes on the plantar surface of the feet, indicates a decrease in the filtration capacity of the renal tubules.Lactating animals experience an increased physiological load on the liver, which is expressed by an increase in triacylglycerols throughout the adaptation.
\end{abstract}

\section{Introduction}

Industrial animal husbandry technologies have undergone substantial modernization under the conditions of intensification. There are changes in the materials used to build livestock buildings; revisions to animal feeding norms depending on the rearing technology and the objectives set; changes in the feed base, zoohygienic parameters and methods of implementation. Like other animal husbandry sectors, rabbit breeding does not stand still and is developing in a variety of ways. In recent years, apart from the shed technology, it has become widely popular to use industrial cages with different modifications of mesh floors. However, the use of these approaches in the intensification of rabbit breeding does not solve the problem of the high prevalence of pododermatitis on the plantar surface of the feet in rabbits $[8,12]$.

Morphological changes in the foot area are due to various etiological factors, including a mesh floor; hard, traumatic or wet bedding material; and long claws [14].
During ontogenesis, every organism has to adapt to its environment. It is an integral part of the existence of any living organism. There are now many publications on the subject. The main ones focus on the study of transport stress, adaptation to increased physical exertion or conversely to hypokinesia. The process of adaptation has been studied at different levels of organization of living organisms: from the physiological, biochemical, organismal, population and evolutionary levels $[9,11,13,15]$.

At the organism level, work most frequently focuses on the study of adaptive changes induced by acute stressors.

During the adaptation process, there is a narrowing or expansion of the homeostatic range - adaptive homeostasis [10].

The purpose of our study was to investigate the dynamics of biochemical parameters in rabbits of different sex and physiological condition depending on the stage of the adaptation process. 


\section{Material and methods}

The testing site was the rabbit breeding research laboratory of the Agrotechnopark Research and Development Centre of the Belgorod State Agrarian University.

To achieve the aim of the study, we ran three series of experiments:

On 7-8 month old stud bucks $(\mathrm{n}=15)$;

On in-kindle does (last third of gestation) of 4-5 months of age $(n=15)$;

On lactating does (30 days of lactation) 6-7 months old, $(n=15)$.

Depending on the changes on the plantar surface of the feet and the classification of the adaptation process according to the stress degree of the body's regulatory systems (according to Baevsky R.M., 1979), we classified all animals into three groups:

Group I included a state bordering on the physiological norm with minimal stress on the regulatory mechanisms. It manifests an absence of visible changes on the plantar part of the hind feet.

Group II includes the stress state of the regulatory mechanisms. It is characterized by alopecia, white callus and hyperkeratosis on the plantar surface of the hind limbs.

Group III includes a state of regulatory overstress. It is accompanied by the development of extensive alopecia on the plantar surface of the hind limbs and the appearance of marked haemorrhagic changes in callus formation.

The animals lived individually in cages of the KSK-1 type, on dry fodder with constant access to water.

We collected blood from the femoral vein (vena saphena).

We determined the content of total protein by refractometry and its fractions by nephelometric determination [3].

The determination of basic biochemical parameters used the photometric method on a KFK-2 photocalorimeter.

We processed the experimental data using Microsoft Excel and adjusted it for the Student's t-test. The results were considered reliable at $\mathrm{p}<0.05$.

\section{Results and discussion}

Table1 presents an analysis of blood parameters characterizing the metabolic status of bucks against the background of changes in the plantar surface of the feet and the state of the adaptation process.

Table 1 shows that plasma levels of total protein in bucks of group II (with state of regulatory stress) were $11.4 \%$ higher $(\mathrm{p}<0.05)$ in comparison with group I animals (with minimal regulatory stress). In group III (with hemorrhagic changes on the plantar surface of the feet - the state of overstress of the regulatory mechanisms of adaptation) we also noted a significant increase in total protein concentration by $3.94 \mathrm{~g} / \mathrm{l}(5.8 \%)$ relative to group II and by $10.90 \mathrm{~g} / \mathrm{l}(17.8 \%)$ relative to the group I.
The bucks with absent plantar surface changes in the feet had the following distribution of total protein fractions qualitatively and quantitatively: albumin $77.0 \%, \alpha$-globulin $8.8 \%, \beta$-globulin $7.0 \%, \gamma$-globulin $7.3 \%$.

The values given in Table 1 for rabbits with changes in the hindfoot area manifested by alopecia, hyperkeratosis and white callus did not differ significantly from those of Group I.

Group III showed a significant decrease in albumin compared to Group I and an increase in $\alpha$ - and $\beta$-globulin, while Group II animals showed a decrease in albumin and an increase in $\alpha$-globulin.

Table 1. Blood values of stud bucks with varying degrees of regulatory stress

\begin{tabular}{|l|l|l|l|}
\hline \multirow{2}{*}{ Indicators } & Groups & \multicolumn{3}{l|}{} \\
\cline { 2 - 4 } & I & II & III \\
\hline Total protein, g/l & $61.14 \pm 2.02$ & $68.10 \pm 0.75^{*}$ & $72.04 \pm 3.49^{*}$ \\
\hline Albumin, g/l & $47.03 \pm 1.55$ & $51.69 \pm 1.44$ & $47.57 \pm 2.70$ \\
\hline$\alpha$-globulins, g/l & $5.34 \pm 0.31$ & $5.74 \pm 0.63$ & $8.04 \pm 0.35^{* \bullet \bullet}$ \\
\hline$\beta$-globulins, g/l & $4.30 \pm 0.47$ & $5.09 \pm 0.20$ & $6.03 \pm 0.36^{*}$ \\
\hline$\gamma$-globulins, g/l & $4.47 \pm 0.72$ & $5.57 \pm 1.02$ & $10.38 \pm 2.78$ \\
\hline $\begin{array}{l}\text { Creatinine, } \\
\mu \mathrm{mol} / \mathrm{l}\end{array}$ & $147.12 \pm 29.98$ & $120.12 \pm 12.25$ & $105.36 \pm 42.72$ \\
\hline $\begin{array}{l}\text { Total bilirubin, } \\
\mu \mathrm{mol} / \mathrm{l}\end{array}$ & $8.21 \pm 0.54$ & $2.94 \pm 0.28^{* * *}$ & $10.64 \pm 2.99^{\bullet}$ \\
\hline Urea, $\mu \mathrm{mol} / \mathrm{l}$ & $8.72 \pm 0.78$ & $4.40 \pm 0.38^{* *}$ & $8.78 \pm 0.79^{\bullet \bullet}$ \\
\hline $\begin{array}{l}\text { Uric } \\
\mu \mathrm{mol} / \mathrm{l}\end{array}$ & $37.38 \pm 13.39$ & $34.26 \pm 4.43$ & $28.80 \pm 9.69$ \\
\hline ALT, $\mu \mathrm{mol} / \mathrm{s} \cdot 1$ & $0.32 \pm 0.03$ & $0.17 \pm 0.01^{* *}$ & $0.32 \pm 0.04^{\bullet \bullet}$ \\
\hline AST, $\mu \mathrm{mol} / \mathrm{s} \cdot 1$ & $0.34 \pm 0.02$ & $0.21 \pm 0.03^{* *}$ & $0.29 \pm 0.01^{\bullet}$ \\
\hline $\begin{array}{l}\text { Alkaline } \\
\text { phosphatase, } \\
\text { nmol/s } 1 \mathrm{l}\end{array}$ & $1011.4 \pm 123.2$ & $390.2 \pm 70.1^{* *}$ & $316.4 \pm 46.5^{* * *}$ \\
\hline $\begin{array}{l}\text { Triacylglycerol, } \\
\mu \mathrm{mol} / \mathrm{l}\end{array}$ & $0.46 \pm 0.05$ & $1.74 \pm 0.36^{*}$ & $0.43 \pm 0.04^{\bullet}$ \\
\hline $\begin{array}{l}\text { Cholesterol, } \\
\text { mmol/l }\end{array}$ & $1.49 \pm 0.28$ & $1.00 \pm 0.12$ & $1.36 \pm 0.15$ \\
\hline Glucose, $\mu \mathrm{mol} / 1$ & $5.71 \pm 0,42$ & $6.93 \pm 0.56$ & $3.92 \pm 0.66^{\bullet \bullet}$ \\
\hline
\end{tabular}

Note: Hereafter, there is the difference regarding Group I *p<0.05; ** $\mathrm{p}<0.01 ; * * * \mathrm{p}<0.001$;

in relation to II $-^{\bullet} \mathrm{p}<0.05 ;^{\bullet \bullet} \mathrm{p}<0.01 ;{ }^{\bullet \bullet} \mathrm{p}<0.001$.

The serum creatinine content with the progression of structural changes on the plantar surface of the hind limbs showed a decreasing tendency from stage to stage. Thus, in rabbits of the group II it decreased by $18.4 \%$ relative to group I $(120.12 \pm 12.25$ vs $147.12 \pm 29.98 \mu \mathrm{mol} / \mathrm{l})$, and in rabbits of the group III it decreased by $14.76 \mu \mathrm{mol} / \mathrm{l}$ relative to the group II and by $41.76 \mu \mathrm{mol} / 1$ relative to the group I.

According to the table, the level of total bilirubin in group I is $8.21 \pm 0.54 \mu \mathrm{mol} / \mathrm{l}$. Group II showed a sharp 2.8fold decrease to $2.94 \pm 0.28 \mu \mathrm{mol} / \mathrm{l}(\mathrm{p}<0.05)$, while group III had a significant increase of $7.70 \mu \mathrm{mol} / 1$ in comparison with group II and $2.43 \mu \mathrm{mol} / \mathrm{l}$ in comparison with group I. It should be noted that we did not detect direct bilirubin in the blood of rabbits of all groups.

In bucks of group I the level of urea was $8.72 \pm 0.78$ $\mu \mathrm{mol} / 1$, in group II it was significantly lower by 4.32 
$\mu \mathrm{mol} / \mathrm{l}(\mathrm{p}<0.01)$, in group III the value of this parameter increased twice in comparison with group II (with the same degree of reliability), but there were no significant changes in comparison with group I. In other words, the urea concentration at the lowest and highest states of regulatory stress is the same.

Group I of rabbits had uric acid levels of $37.38 \pm 13.39$ $\mu \mathrm{mol} / \mathrm{l}$, Group II had a decrease of $8.3 \%$ and Group III had a decrease of $15.9 \%$. That is, as the stress of physiological adaptation developed, we noted a consistent downward trend from $37.38 \pm 13.39$ to $28.80 \pm 9.69 \mu \mathrm{mol} / 1$.

The alanine aminotransferase activity (ALT) in group I was $0.32 \pm 0.03 \mu \mathrm{mol} / \cdot \mathrm{L}$, while in group II, there was a significant decrease $(\mathrm{p}<0.01)$ of $45.8 \%$ and in group III an increase to the initial values of group I.

The group I of bucks had aspartate aminotransferase activity (AST) equal to $0.34 \pm 0.02 \mu \mathrm{mol} / \cdot 1$, while in group II it decreased significantly by $38.93 \%(\mathrm{p}<0.01)$, but in group III it increased by $0.09 \mu \mathrm{mol} / \cdot 1(\mathrm{p}<0.01)$, but still remained lower than in group I of bucks (Table 1 ).

The enzymatic activity of alkaline phosphatase in group I is $1011.4 \pm 123.2 \mathrm{nmol} / \cdot 1$, in group II it decreases by $61.4 \%(\mathrm{p}<0.01)$, in group III it decreases by $73.8 \mathrm{nmol} / \cdot 1$ and in group I it decreases by $695.0 \mathrm{nmol} / \cdot 1(\mathrm{p}<0.001)$.

The content of triacylglycerols in the blood of rabbits in group I was $0.46 \pm 0.05 \mu \mathrm{mol} / \mathrm{l}$, in group II there was a significant increase of 3.8 times and a significant decrease of 4 times in group III. Eventually, the value of this index at the stage of overstress in the regulatory mechanisms of physiological adaptation processes, group III, was equal to that characteristic of group I (with minimum stress on these processes).

In terms of the development of physiological adaptation stress states, we observed no significant difference in cholesterol concentration between stages 1 and 3 (group I and III, bucks), whereas, in stage 2 of the development of the regulatory mechanism of adaptation (group II), the amount of cholesterol was $32.9 \%$ lower than in group I and $26.5 \%$ lower than in group III.

Blood glucose concentration analysis showed the following results: in group I of bucks were within $5.71 \pm 0.42 \mu \mathrm{mol} / 1$, in group II there was a $21.5 \%$ increase, group III showed a $43.4 \%$ decrease $(\mathrm{p}<0.01)$ compared to group II.

Table 2 presents an analysis of the blood parameters characterizing the metabolic status of pregnant does against the background of the development of physiological adaptation stress to cage husbandry technology.

Table 2.- Blood parameters of pregnant rabbits with different degrees of regulatory stress

\begin{tabular}{|c|c|c|c|}
\hline \multirow{2}{*}{ Indicators } & \multicolumn{3}{|l|}{ Groups } \\
\hline & $\mathrm{I}$ & II & III \\
\hline Total protein, g/l & $62.87 \pm 10.06$ & $52.08 \pm 3.69$ & $61.46 \pm 4.32$ \\
\hline Albumin, $\mathrm{g} / \mathrm{l}$ & $42.80 \pm 3.34$ & $37.25 \pm 3.55$ & $37.98 \pm 2.17$ \\
\hline$\alpha$-globulins, g/l & $6.43 \pm 0.58$ & $5.76 \pm 1.29$ & $7.82 \pm 0.47$ \\
\hline$\beta$-globulins, $\mathrm{g} / \mathrm{l}$ & $3.72 \pm 1.32$ & $4.28 \pm 0.29$ & $4.66 \pm 0.71$ \\
\hline$\gamma$-globulins, g/l & $9.95 \pm 5.23$ & $4.79 \pm 0.66$ & $10.98 \pm 1.90^{\bullet}$ \\
\hline Creatinine, $\mu \mathrm{mol} / \mathrm{l}$ & $69.40 \pm 10.95$ & $145.13 \pm 18.15^{* *}$ & $113.20 \pm 10.41^{*}$ \\
\hline Total bilirubin, $\mu \mathrm{mol} / \mathrm{l}$ & $2.05 \pm 1.29$ & $3.61 \pm 1.10$ & $3.55 \pm 0.47$ \\
\hline Urea, $\mu \mathrm{mol} / 1$ & $3.13 \pm 0.90$ & $6.28 \pm 1.72$ & $6.60 \pm 0.45 * *$ \\
\hline Uric acid, $\mu \mathrm{mol} / 1$ & $35.23 \pm 4.95$ & $37.73 \pm 8.31$ & $26.30 \pm 6.60$ \\
\hline ALT, $\mu \mathrm{mol} / \mathrm{s} \cdot \mathrm{l}$ & $0.34 \pm 0.04$ & $0.25 \pm 0.11$ & $0.20 \pm 0.02 *$ \\
\hline AST, $\mu \mathrm{mol} / \mathrm{s} \cdot 1$ & $0.24 \pm 0.05$ & $0.28 \pm 0.04$ & $0.20 \pm 0.03$ \\
\hline Alkaline phosphatase, $\mathrm{nmol} / \mathrm{s} \cdot 1$ & $418.90 \pm 170.24$ & $214.73 \pm 43.87$ & $166.72 \pm 28.98^{*}$ \\
\hline Triacylglycerol, $\mu \mathrm{mol} / 1$ & $0.48 \pm 0.01$ & $1.10 \pm 0.41$ & $0.71 \pm 0.25$ \\
\hline Cholesterol, mmol/l & $0.62 \pm 0.25$ & $0.40 \pm 0.06$ & $0.48 \pm 0.15$ \\
\hline Glucose, $\mu \mathrm{mol} / \mathrm{l}$ & $4.98 \pm 0.22$ & $5.23 \pm 1.33$ & $3.70 \pm 0.68$ \\
\hline \multicolumn{2}{|c|}{$\begin{array}{l}\text { Table } 2 \text { shows that there are no significant differences } \\
\text { in the total protein, albumin, } \alpha \text { - and } \beta \text {-globulin levels in the } \\
\text { serum of does, depending on the stages of physiological } \\
\text { adaptation. } \\
\text { It is clearly seen that } \gamma \text {-globulin tends to decrease in } \\
\text { stage II of the adaptation process, followed by a significant }\end{array}$} & \multicolumn{2}{|c|}{$\begin{array}{l}\text { The level of creatinine, one of the end products of } \\
\text { protein breakdown, in does of groups II and III exceeds } \\
\text { that in the blood of group I with different degrees of } \\
\text { reliability, indicating a different degree of increase in } \\
\text { functional load on the kidneys during pregnancy } \\
\text { depending on the degree of manifestation of adaptive } \\
\text { changes. }\end{array}$} \\
\hline
\end{tabular}

increase in the development of a state of regulatory overstress. This indicates an activation of immunocompetent organ function. 
The concentration of total bilirubin in rabbits of all groups did not differ significantly in the development of the adaptation process.

While in group I the serum urea content was $3.13 \pm 0.90$ $\mu \mathrm{mol} / 1$, in groups II and III it increased 2 or more times (in group III it is reliably). This reflects the increasing filtration load on the urinary system.

Uric acid levels fluctuated insignificantly between $35.23 \pm 4.95$ and $26.30 \pm 6.60 \mu \mathrm{mol} / 1$ by observational stage.

ALT enzymatic activity in group $\mathrm{I}$ is $0.34 \pm 0.04$ $\mu \mathrm{mol} / \cdot \mathrm{L}$, in groups II and III it decreases consistently by $26.5 \%$ and $20.0 \%$ relative to the previous group, and in goup III it is $41.2 \%(\mathrm{p}<0.05)$, or 1.7 times lower than values determined in animals with minimal stress of regulatory systems.

AST activity levels in all pregnant does studied ranged from $0.24 \pm 0.05$ to $0.20 \pm 0.03 \mu \mathrm{mol} / \mathrm{s} \cdot 1$. In other words, there were no significant changes in the activity of this enzyme during the development of adaptive changes.

As with the ALT enzyme, alkaline phosphatase activity decreases consistently across stages of observation $(\mathrm{p}>0.05)$.

The triacylglycerol content of pregnant does in group I did not significantly vary from $0.48 \pm 0.01$ to $0.71 \pm 0.25$ $\mu \mathrm{mol} / 1$.

Cholesterol and glucose levels had no significant differences between the groups, depending on the stages of physiological adaptation processes (with different degrees of stress on regulatory mechanisms).

Table 3. Blood values of lactating does with different degrees of regulatory stress

\begin{tabular}{|c|c|c|c|}
\hline \multirow{2}{*}{ Indicators } & \multicolumn{3}{|l|}{ Groups } \\
\hline & $\mathrm{I}$ & II & III \\
\hline $\begin{array}{l}\text { Total protein, } \\
\mathrm{g} / \mathrm{l}\end{array}$ & $66,30 \pm 1,51$ & $66,93 \pm 3,80$ & $70,55 \pm 5,25$ \\
\hline Albumin, $\mathrm{g} / \mathrm{l}$ & $45,18 \pm 1,63$ & $45,32 \pm 1,25$ & $47,57 \pm 0,04$ \\
\hline$\alpha$-globulins, g/l & $7,07 \pm 0,40$ & $9,76 \pm 1,18$ & $9,64 \pm 1,73$ \\
\hline$\beta$-globulins, g/l & $5,66 \pm 1,46$ & $4,80 \pm 0,63$ & $4,82 \pm 1,10$ \\
\hline$\gamma$-globulins, g/l & $8,38 \pm 1,01$ & $7,05 \pm 2,13$ & $8,53 \pm 2,46$ \\
\hline $\begin{array}{l}\text { Creatinine, } \\
\mu \mathrm{mol} / \mathrm{l}\end{array}$ & $119,20 \pm 11,88$ & $131,63 \pm 14,24$ & $149,15 \pm 45,85$ \\
\hline $\begin{array}{l}\text { Total bilirubin, } \\
\mu \mathrm{mol} / 1\end{array}$ & $5,87 \pm 0,77$ & $4,11 \pm 0,87$ & $3,34 \pm 2,69$ \\
\hline Urea, $\mu \mathrm{mol} / 1$ & $6,30 \pm 0,70$ & $5,50 \pm 1,34$ & $7,45 \pm 1,05$ \\
\hline $\begin{array}{l}\text { Uric } \\
\mu \mathrm{mol} / 1\end{array}$ & $38,48 \pm 7,84$ & $49,83 \pm 5,81$ & $62,75 \pm 11,55$ \\
\hline ALT, $\mu \mathrm{mol} / \mathrm{s} \cdot 1$ & $0,25 \pm 0,04$ & $0,16 \pm 0,01$ & $0,18 \pm 0,01$ \\
\hline $\mathrm{AST}, \mu \mathrm{mol} / \mathrm{s} \cdot \mathrm{l}$ & $0,26 \pm 0,01$ & $0,23 \pm 0,04$ & $0,23 \pm 0,01$ \\
\hline $\begin{array}{l}\text { Alkaline } \\
\text { phosphatase, } \\
\text { nmol/s·l }\end{array}$ & $522,08 \pm 135,42$ & $265,00 \pm 27,32$ & $297,00 \pm 84,30$ \\
\hline $\begin{array}{l}\text { Triacylglycerol, } \\
\mu \mathrm{mol} / 1\end{array}$ & $0,71 \pm 0,04$ & $0,72 \pm 0,04$ & $1,04 \pm 0,04 * * * \bullet \bullet$ \\
\hline $\begin{array}{l}\text { Cholesterol, } \\
\mathrm{mmol} / \mathrm{l}\end{array}$ & $1,51 \pm 0,16$ & $1,27 \pm 0,28$ & $1,42 \pm 0,07$ \\
\hline Glucose, $\mu \mathrm{mol} / \mathrm{l}$ & $4,15 \pm 0,57$ & $4,66 \pm 1,74$ & $6,14 \pm 3,34$ \\
\hline
\end{tabular}

In contrast to pregnant rabbits, which have some reliable differences in biochemical blood parameters depending on the stages of physiological adaptation processes, in lactating does we did not find reliable differences among all the studied metabolic status parameters, except for the concentration of triacylglycerols (Table 3).

Table 3 shows that this lipid indicator in group III was significantly different from both groups I and II by $47 \%$ and $44 \%$ respectively $(\mathrm{p}<0.001)$. This indicates an increasing functional load on hepatocytes, against the background of a decreasing trend in their enzymatic activity (ALT, AST, alkaline phosphatase).

\section{Conclusion}

Based on the results obtained, we can conclude that depending on the stage of the stress of the adaptation process, stud backs showed an increase in the compensatory reaction accompanied by hyperproteinemia on the background of a decrease in relative albumin values, which is caused by an increase in capillary permeability in the plantar surface of feet and migration of some albumin into adjacent tissues, and redistribution between the protein fractions [7]. A sharp decrease in total bilirubin in the second stage of the adaptation process against the background of a decrease in ALT, AST and alkaline phosphatase activity, indicates an increase in the functional activity of the liver with prolonged preservation of hepatocyte integrity [2,4]. An increase in total bilirubin and the enzymatic activities of ALT and AST with a further decrease in alkaline phosphatase during the third stage of the adaptation process may indicate the development of decompensatory mechanisms in functioning hepatocytes [5].

The compensatory reactions of pregnant rabbits are most evident in the third stage of the adaptation process. These are expressed as an increase in absolute and relative $\gamma$-globulin values, indicating activation of immune factors (7). An increase in creatinine and urea levels during pregnancy in stages II and III of the development of adaptive changes on the plantar surface of the feet indicates a decrease in the filtration capacity of the renal tubules (6).

During lactopoiesis, there is a tendency for the biochemical parameters studied to change during different periods of the adaptation process, except for triacylglycerol levels. Its rise indicates an increasing functional load on the liver[3].

\section{References}

1. R.M .Baevsky Prediction on the edge of norm and pathology (Moscow: Medicine, 1979) 
2. M.A. Verotchenko Bulletin of Tuva State University No. 2 Natural and Agricultural Sciences,. 2, 50-55 (2018)

3. Ed. I.P. Kondrakhin Methods of veterinary clinical laboratory diagnostics: Reference book (Moscow: KolosS, 2004)

4. T. L. Pilat, L. P. Kuzmina, M.M. Koliaskina, L.M. Bezrukavnikova Experimental and Clinical Gastroenterology, 11 (183), 118 - 125,(2020)

5. N.V. Solovyova Scientific Notes of Petrozavodsk State University, 8-1(145), 52 - 58, (2014)

6. M.S. Surovikina, N.P. Velichkina, V. V. Surovikin Medical Alphabet, 3 (1), 9-11, (2013)

7. V.M. Kholod Blood serum proteins in clinical and experimental veterinary medicine (Minsk: Urajai, 1983).

8. N.S. Khokhlova Semenyutin V.V. Proceedings of the XXIV International Scientific-Production Conference "Innovative Solutions in Agricultural Science - a Look into the Future", 27-28 May 2020), Vol. 1. Maysky.

9. W. Hu, T. Ye, Y. Yang, et al. BMC Vet Res, 16, 347 (2020)

10. J.A. Kelvin Davies Molecular Aspects of Medicine, 49, 1-7, (2016)

11. S.L. McGee, M. Hargreaves Nat Rev Endocrinol, 16, 495-505 (2020)

12. S. Ruchtia, G. Kratzerb, R. Furrerb, S. Hartnackd, H. Würbele, S.G. Gebhardt-Henrich Preventive Veterinary Medicine, 166, 56-64 (2019)

13. A.I. Weber, K. Krishnamurthy, A. L. Fairhall Annual Review of Vision Science, 5, 427-449 (2019)

14. P. Wolf, R. Speers, M.G. Cappai Research in Veterinary Science, 129, 1-5, (2020)

15. J. Xin, H. Zhang, Y. He, et al. Nat Commun, 11, 4928, (2020) 